\title{
Effects of plant-derived anti-leukemic drugs on individualized leukemic cell population profiles in Egyptian patients
}

\author{
MOURAD A. M. ABOUL-SOUD ${ }^{1,2}$, HANY A. EL-SHEMY ${ }^{1}$, KHALID M. ABOUL-ENEIN ${ }^{3}$, \\ ALI M. MAHMOUD ${ }^{1,4}$, AHMED M. AL-ABD ${ }^{5}$ and DAVID A. LIGHTFOOT 6
}

\begin{abstract}
${ }^{1}$ Faculty of Agriculture Research Park (FARP) and Department of Biochemistry, Faculty of Agriculture, Cairo University, Giza 12613, Egypt; ${ }^{2}$ Chair of Medical and Molecular Genetics Research, Department of Clinical Laboratory Sciences, College of Applied Medical Sciences, King Saud University, Riyadh 11433, Kingdom of Saudi Arabia; ${ }^{3}$ Department of Clinical Pathology, National Cancer Institute, Cairo University, Cairo 12513; ${ }^{4}$ Center for Aging and Associated Diseases (CAAD), Helmy Institute for Medical Science (HIMS), Zewail City for Science and Technology, 6th of October City, Giza 12588; ${ }^{5}$ Department of Pharmacology, Medical Division, National Research Centre, Cairo 11796, Egypt; ${ }^{6}$ Genomics Core-Facility, Southern Illinois University, Carbondale, IL 62901, USA
\end{abstract}

Received September 21, 2015; Accepted November 13, 2015

DOI: $10.3892 / \mathrm{ol} .2015 .3916$

\begin{abstract}
Leukemias are a group of cancer types that originate from blood-forming tissues. In this disease, an abnormally large number of immature white blood cells is produced by the bone marrow. The relationship between treatments with plant-derived drugs and leukemia-associated immunophenotypes (LAIPs) of clinically isolated leukemia cells has yet to be established. The aim of the present study was to develop a preliminary clinical prognostic map for commonly expressed LAIPs in patients clinically diagnosed with leukemia, as well as to assess the potential involvement of LAIPs in the response rate to 10 natural products of plant origin. An increased expression of LAIPs, including CD4, CD14, CD33 and CD34, was considered a surrogate marker of the desired response of leukemia cells to treatment with plant-derived drugs. By contrast, the increased expression of the LAIPs, MPO and DR, was associated with poor prognostic outcomes following treatment with the plant-derived drugs. The results showed that 5 of the 10 plant-derived drugs tested induced the expression of several desirable LAIPs biomarkers.
\end{abstract}

Correspondence to: Professor Mourad A. M. Aboul-Soud, Chair of Medical and Molecular Genetics Research, Department of Clinical Laboratory Sciences, College of Applied Medical Sciences, King Saud University, P.O. Box 10219, Riyadh 11433, Kingdom of Saudi Arabia

E-mail: maboulsoud@ksu.edu.sa

Professor Hany A. El-Shemy, Faculty of Agriculture Research Park (FARP) and Department of Biochemistry, Faculty of Agriculture, Cairo University, Giza 12613, Egypt

E-mail: helshemy@hotmail.com

Key words: leukemia, immunophenotyping, biomarkers, natural products, surrogate markers
These findings clearly highlight the potential treatment efficacy of certain plant-derived drugs against leukemic cell types.

\section{Introduction}

Leukemias are a group of cancers that originate from blood-forming tissues. The name of the disease is derived from the Greek word 'leukos' for 'white blood' (1). In this disorder an abnormally large number of immature white blood cells (WBCs) is produced by the bone marrow. These leukemic WBCs eventually replace the normal ones, resulting in the clinical manifestation of anemia, leaving the body more susceptible to infection (1). Leukemia is classified into four main categories or subtypes according to cell type and rate of growth: acute lymphocytic leukemia (ALL) derived from immature T- or B-lymphocytes, most common in children; acute myeloid leukemia (AML) from immature myeloid cells, most common in adults; chronic lymphocytic leukemia (CLL) from mature B-lymphocytes, mostly an adult disorder; and chronic myelogenous leukemia (CML) from granulocyte precursors, most common in adults $(2,3)$.

Leukemia is the most common form of cancer in children worldwide, except in Africa, where non-Hodgkin lymphomas predominate (4). In the US, for example, the predominant types of pediatric cancers (ages 0-19) are leukemia (subtype ALL, 26\%), followed by cancer of the brain and central nervous system (18\%), and lymphoma (14\%) (5). Statistics have shown that leukemia is 1 of the 10 most common malignancies in Jordan, Lebanon, Bahrain, Egypt, Iraq, Libya, Kuwait, Oman, Qatar, Saudi Arabia, Syria, and the UAE. The most common leukemic type is ALL followed by AML (Kuwait, 44 and 32\%; and Saudi Arabia, 34 and 25\%, respectively) (6). The two most prevalent types of leukemia in children and adolescents are ALL and AML in both Arab countries (6) and the US (5). Chronic leukemias are extremely rare in children and adolescents. ALL accounts for $80 \%$ of leukemic cases in children and $56 \%$ in adolescents. AML is less common 
in children compared to ALL, comprising $15 \%$ of leukemic cases in children and $31 \%$ in adolescents (5). Improved treatment for ALL in childhood has increased the 5-year survival rate from $57 \%$ in the period $1975-1979$ to $90 \%$ in the period 2003-2009 (5). In Egypt, leukemia-associated mortality accounts for $0.1 \%$, and is ranked the 3rd most common mortality-causing neoplasm in the Egyptian population, directly behind mortalities from bladder and breast cancers, and the 8th worldwide. Although advances in treatment have increased the survival rate for many childhood cancers, the disease remains the second leading cause of death (following accidents) in children aged 5-14 (3,4,7-9).

Natural products are considered an essential research theme at the interface of biology and chemistry. A natural product is simply defined as a small molecule that is produced by a biological source (10). Historically, natural products have proven a valuable source for new medicines, drug identification and development worldwide, and many of these are plant-derived (11). Intensified efforts to identify new agents for the treatment of leukemia have been made globally. In the early 1900 s, $80 \%$ of medicines were obtained from roots, barks and leaves and it is estimated that $\sim 25 \%$ of drugs prescribed today originate from plants (12-14). The plant kingdom, with $\sim 250,000$ higher species, has always constituted a key source of new chemical entities (NCEs) for active pharmaceutical ingredients and lead compounds (15). Currently, isolation and purification of the active fraction(s) or active ingredient among potentially active natural products is receiving great scientific and industrial interest (16). To this end, several chemotherapeutic drugs derived from plants, such as vinblastine, taxol, camptothecin and podophyllotoxin have been used in medical tumor management (17). However, it has been estimated that only $5-15 \%$ of 250,000 species of higher plants have been screened systematically as natural bioactive compounds (16). In addition, only a small percentage of the current collection (comprising $\sim 30,000$ species) at the US National Cancer Institute was reportedly been screened for pharmacological activity until recently, and currently large numbers are constantly being tested for their possible therapeutic value (14). Thus, the plant kingdom comprises numerous species containing NCEs of medicinal value and potential pharmaceutical applications that have yet to be identified. Therefore, NCEs that are specifically active against leukemia may be identified de novo by predictions of structure and/or function (16). The most important criterion among plant-derived anticancer compounds is their wide safety margins between therapeutic and toxic doses.

Different types of leukemia express on their plasma membranes particular subsets of the 247 defined cluster of differentiation (CD) antigens, which may resemble those of precursor cells along the lineages of differentiation to mature myeloid and lymphoid leukocytes. CD antigens associated with the plasma membranes of leukocytes may be molecules involved in a variety of functions such as cell-cell interactions, cytokine receptors, cell signaling, ion channels, transporters, enzymes, immunoglobulins (IGs), or adhesion molecules (18). As cells differentiate along particular lineages, the expression of CD antigens is altered. Currently, CDs are commonly employed for the identification and investigation of cell surface molecules providing targets for immunophenotyping of cells.
In this context, accurate diagnosis of hematological malignancies enables the selection of the most effective treatment protocol $(18,19)$. Current diagnosis of acute leukemias (ALs) is based on the morphology and cytochemistry of the blast cells according to the released World Health Organization (WHO) classification (19). In the present study, we provide a preliminary clinical prognostic map for the so-called leukemia-associated immunophenotypes (LAIPs) in Egyptian patients treated with 10 plant-derived natural products. Honikiol (polyphenol), chrysin (flavone), cholecalciferol (toxiferol, vitamin D3), salicin (alcoholic $\beta$-glucoside), cerulinin (amide antifungal antibiotic), (S)-(-) limonene (terpene), retinyl palmitate (vitamin A ester), mevinolin (fungal metabolite), ${ }_{\text {- }}$-ascorbic acid 6-palmitate (vitamin $\mathrm{C}$ ester) and resveratrol (stilbenoid), were selected for their potential antileukemic effects based on molecular- or literature-based studies (8). The relative response rates and effects of these selected drugs against Egyptian leukemic cell lineages are further examined and discussed.

\section{Materials and methods}

Chemicals and plant-derived drugs. Trypan blue, honikiol, chrysin, cholecalciferol, salicin, cerulinin, (S)-(-) limonene, retinyl palmitate, mevinolin, ${ }_{\mathrm{L}}$-ascorbic acid 6-palmitate and resveratrol were purchased from Sigma Chemical Co. (St. Louis, MO, USA). RPMI-1640 medium, fetal bovine serum and other cell culture materials were purchased from the American Type Culture Collection (ATCC; Houston, TX, USA). Ficoll was purchased from Pharmacia (Uppsala, Sweden). Other materials used were of analytical reagent grade.

Subjects. A total of 15 adult leukemia patients (10 males and 5 females) were included in the study after providing signed informed consent. Investigation involving human participants in this study was approved by the Cairo University Institutional Review Board committee for Clinical Research Ethics. Patients clinically diagnosed with leukemia were admitted to the NCI (Cairo, Egypt) according to the standard operating procedures employed at the NCI. The study design and practices were approved by the NCI. The study was performed on cells harvested from leukemia patients, aged 6-60 years. International protocols governing the ethical treatment of patients were followed.

Clinical examination. The patients were given a definite diagnosis of common ALL in accordance with the 2008 WHO classification (20). In this context, AML, ALL and CML were diagnosed by peripheral blood and bone marrow examination, cytochemistry and immunological markers, as required.

Collection of blood samples and assessment of anti-leukemic effects. Venous blood samples were withdrawn from the peripheral vein while the patient was in the supine position. Mononuclear cells were separated from other blood cells by Ficoll Hypaque $^{\mathrm{TM}}$ density gradient (Pharmacia). The cells were then washed with three changes of phosphate-buffered saline. The cell counts were adjusted to $1 \times 10^{6}$ cells $/ \mathrm{ml}$ (counting both mature and immature cells). The culture medium was prepared using modified Earle's salts supplemented with $1.2 \mathrm{~g} / 1$ sodium carbonate and ${ }_{\text {L-glutamine (Gibco, Grand }}$ 


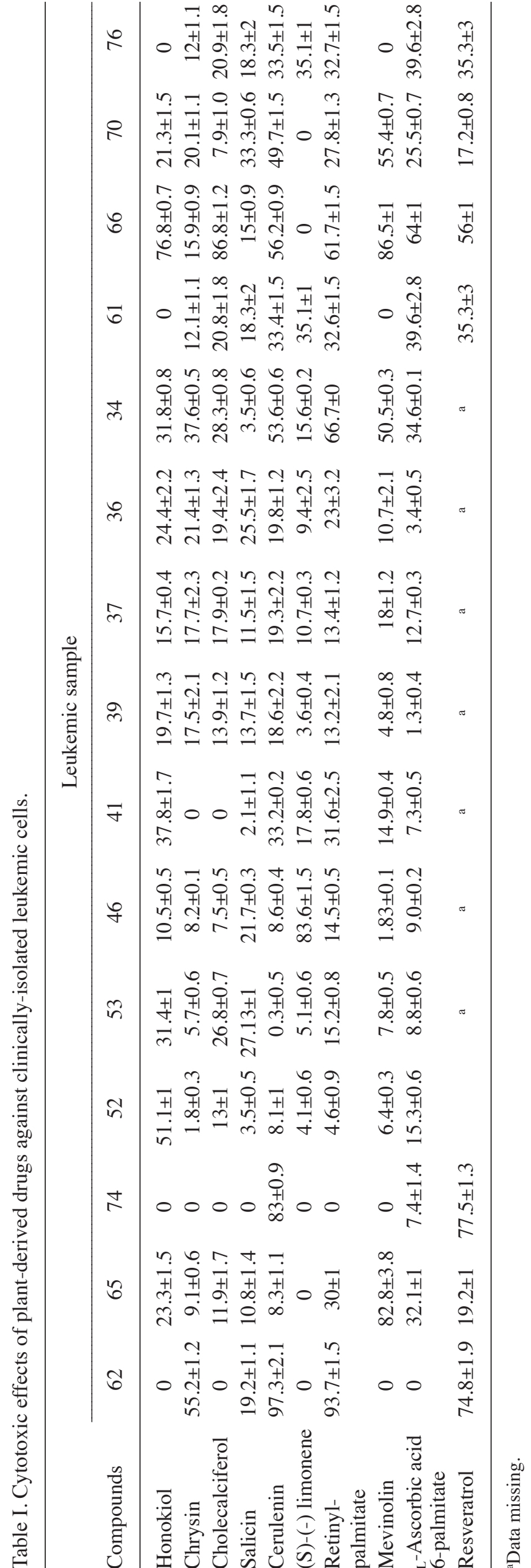

Island, NY, USA), $10 \%$ (w/v) inactivated fetal bovine serum (Gibco), and $100 \mathrm{U} / \mathrm{ml}$ penicillin and $100 \mathrm{mg} / \mathrm{ml}$ streptomycin. The full medium was then filtered through a $0.22 \mu \mathrm{m}$ Millipore filter (Billerica, MA), $1 \mathrm{ml}$ of which was transferred into a $1.8 \mathrm{ml}$ screw-capped sterile plastic tube. Then, $0.1 \mathrm{ml}$ of the cell suspension containing $10^{5}$ cells was added to each of 5 tubes. Subsequently, $0.1 \mathrm{ml}$ of the natural compound under investigation was added to two test tubes, while the other two tubes served as negative and positive controls. The tubes were incubated at $37^{\circ} \mathrm{C}$ in the presence of $5 \%(\mathrm{v} / \mathrm{v}) \mathrm{CO}_{2}$ for $24 \mathrm{~h}$ in the dark, in humidified air. The cells were tested for their viability using the trypan blue exclusion test. A total of 200 cells were counted, and the percentage of viable cells was estimated. Ten natural products of plant origin i.e.,

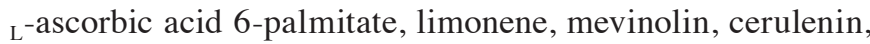
resveratrol, cholecalciferol, retinol palmitate, chrysin, salicine and honikiol, were selected to be tested for their potential anti-leukemic effects.

Cell culture. The human OM10.1, HL-60 and NB4 leukemic cell lines were obtained from the ATCC. The cells were maintained in RPMI-1640 supplemented with $100 \mu \mathrm{g} / \mathrm{ml}$ streptomycin, $100 \mathrm{U} / \mathrm{ml}$ penicillin and $10 \%(\mathrm{w} / \mathrm{v})$ heat-inactivated fetal bovine serum in a humidified, $5 \%(\mathrm{v} / \mathrm{v}) \mathrm{CO}_{2}$ atmosphere at $37^{\circ} \mathrm{C}$. The same 10 natural products were tested for their potential cytotoxic property against the aforementioned cell lines.

Immunophenotypic labeling. Leukemic cell analysis was performed by standard immunofluorescence using monoclonal antibodies directed against the LAIPs CD4, CD14, CD33, CD34, CD22, MPO and DR, as previously reported (21). Each antibody was titrated by serial dilutions. Red blood cells were lysed with ammonium chloride solution, and $1 \times 10^{6}$ cells were used for each test. The antibodies were purchased from BD Biosciences (San Jose, CA, USA), and flow cytometric analyses were performed with a FACSCalibur (BD Biosciences, Mississauga, ON, Canada) flow cytometer.

\section{Results}

Effect of plant-derived drugs on clinically-isolated primary leukemic cell lines. The anti-leukemic effect of natural products under investigation was tested against clinically isolated primary leukemia cell line populations using a trypan blue exclusion assay following exposure for $24 \mathrm{~h}$. Cerulenin exhibited the most potent anti-leukemic effect against the 62NCI clinically isolated leukemia cells by $97.3 \pm 2.1 \%$. By contrast, cerulenin showed the least potent response against $53 \mathrm{NCI}$ by $0.3 \pm 0.6 \%$ (Table I). The order of anti-leukemic effect, expressed as average cytotoxicity percentage, for the drugs under investigation from highest to lowest was: cerulenin (34.9\%), retinyl palmitate (30.9\%), honikiol (22.9\%), mevinolin (22.64\%), ${ }_{\text {L }}$-ascorbic acid 6-palmitate (20.0\%), cholecalciferol (18.3\%), chrysin (15.62\%), salicin (14.9\%), and (S)-(-) limonene (14.7\%). The cytotoxicity of resveratrol was tested on seven lines and exhibited the most potent anti-leukemic effect (54.1\%). The highest cytotoxic response for the tested plant-derived drugs against clinically isolated leukemic cells was observed in AML-M5a cells (66NCI), while the lowest was evident in C-ALL (74NCI and 76NCI) leukemic cells (Fig. 1). 


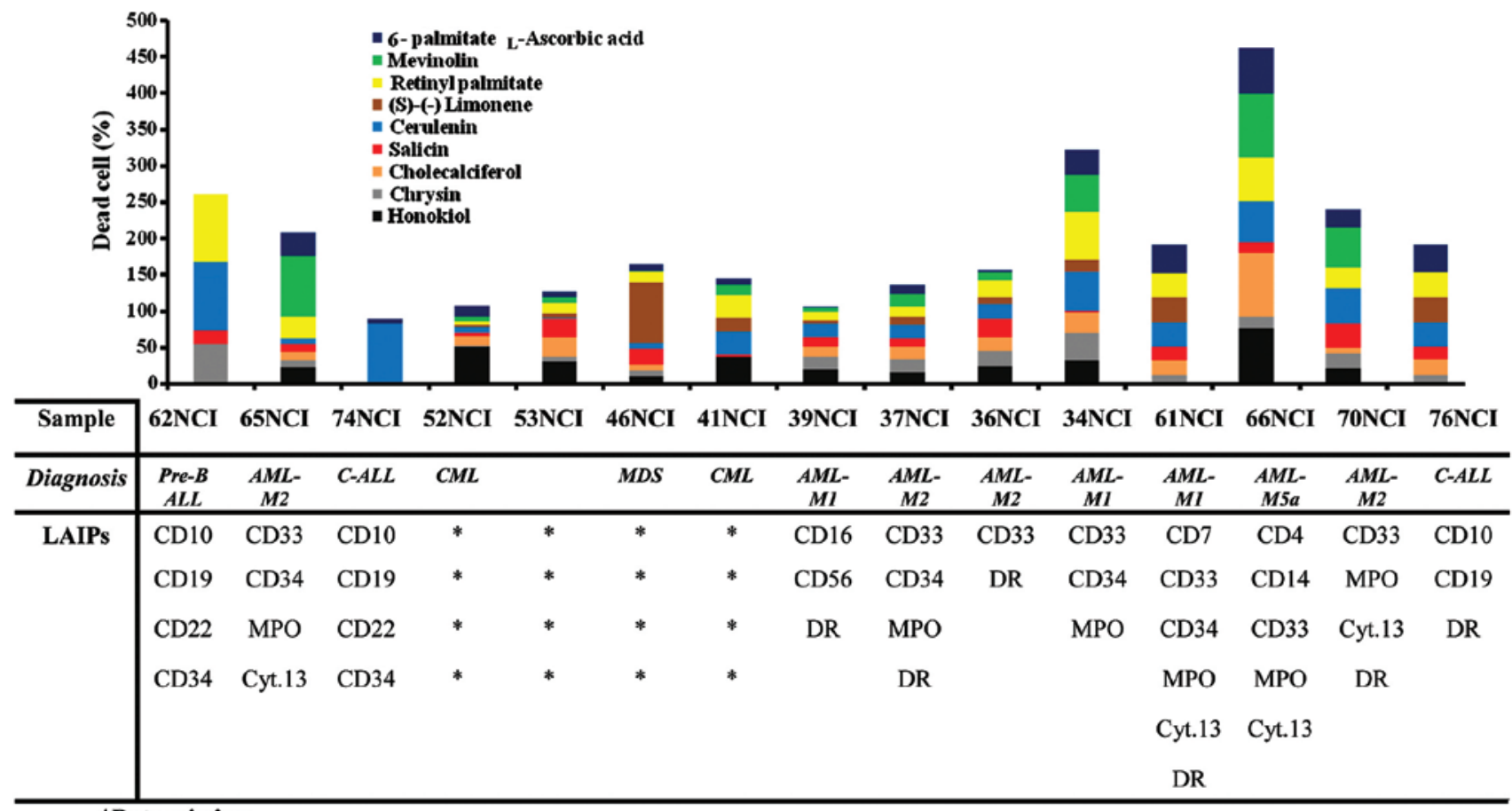

*Data missing

Figure 1. Cytotoxic effect of the selected plant-derived anti-leukemic drugs on clinically isolated leukemia cells. ALL, acute lymphocytic leukemia; AML, acute myeloid leukemia; CML, chronic myelogenous leukemia; NCI, National Cancer Institute; LAIPs, leukemia-associated immunophenotypes.

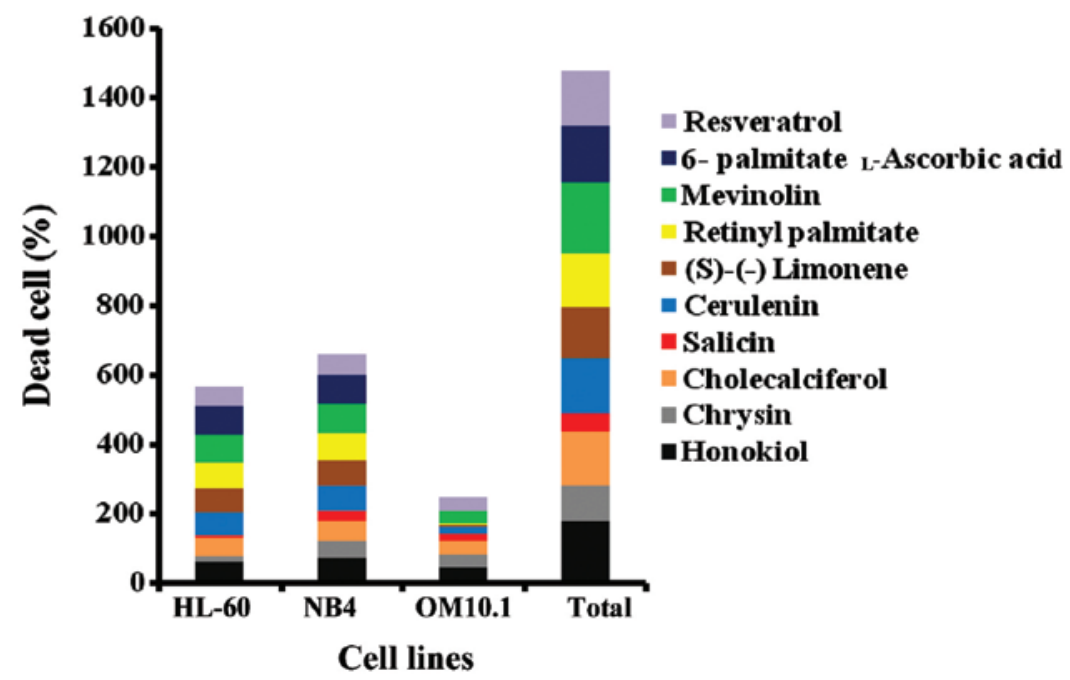

Figure 2. Cytotoxic effect of the selected plant-derived anti-leukemic drugs on 3 standard American Type Culture Collection leukemic cell lines.

Effect of plant-derived drugs on standard ATCC leukemic cell lines. The anti-leukemic effect of the 10 selected plant-derived drugs was investigated against the different stably-transformed leukemia cell lines, OM10.1, HL-60 and NB4, using a trypan blue exclusion assay following exposure for $24 \mathrm{~h}$. Mevinolin and honikiol exhibited the most potent anti-leukemic effects, while salicin showed the least promising response. The anti-leukemic effect of these plant-derived drugs, in descending order, was: mevinolin, honikiol, ${ }_{\mathrm{L}}$-ascorbic acid 6-palmitate, cerulenin, resveratrol, cholecalciferol, retinyl palmitate, (S)-(-) limonene, chrysin and salicin (Fig. 2). The most responsive cell line to the natural products under investigation was NB4 cells, while the most resistant cell line was OM10.1 (Fig. 2).
Association between LAIPs and anti-leukemic effects of the plant-derived drugs. The potential involvement of the immunophenotyping for the presence of certain LAIPs on the response of clinically isolated cells to the selected plant-derived drugs was assessed. The LAIPs of the clinically isolated leukemic cells was examined in relation to their response to the plant-derived drugs. In this context, a diverse response range was observed. The effect of cerulenin against clinically isolated leukemia cells was evidenced by an increased expression of CD10 and CD19. However, a decreased expression of MPO and DR was associated with increased sensitivity of clinically isolated leukemic cells to cerulenin. The efficacy of retinyl palmitate was much lower than cerulinin on the 
A) Honikiol

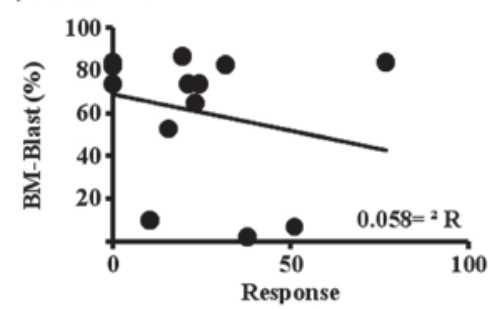

C) Cholicalciferol

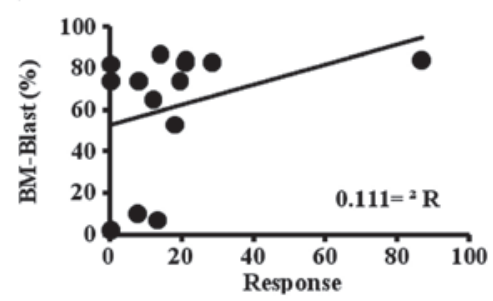

E) Cerulinin

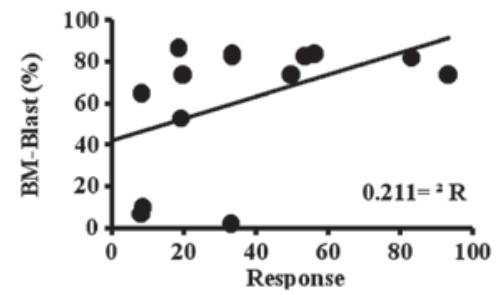

G) Retinyl palmitate

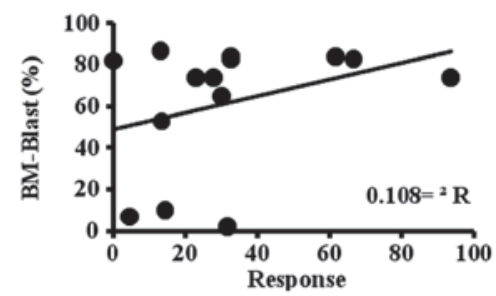

I) L-Ascorbic acid 6- palmitate

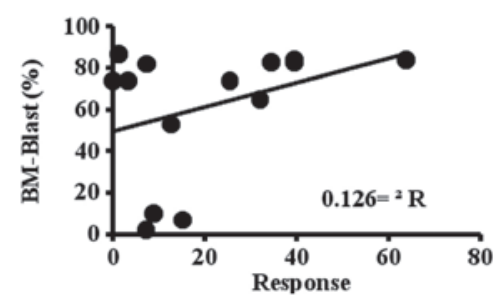

B) Chry sin

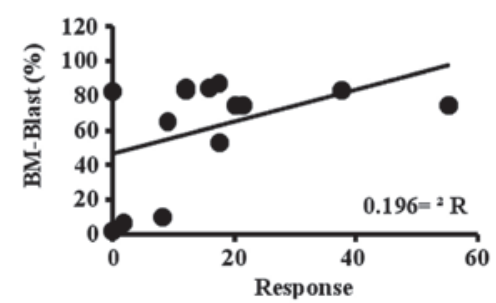

D) Salicin

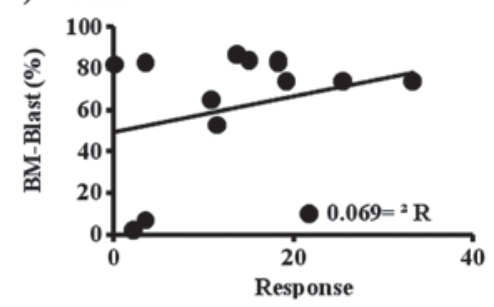

F) (S)-(-) Limonene

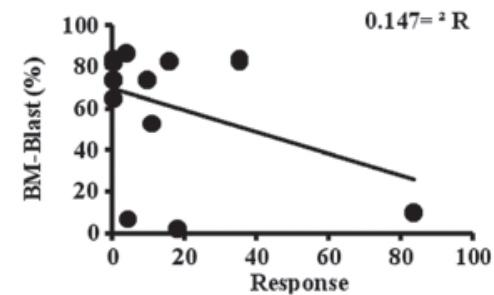

H) Mevinolin

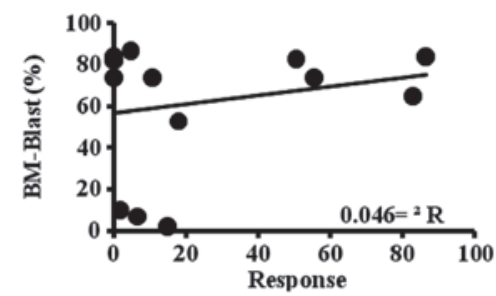

J) Resveratrol

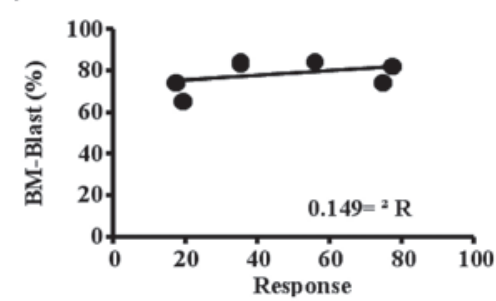

Figure 3. Association between anti-leukemic effect of the selected plant-derived drugs and cell viability.

expression of MPO. On the other hand, the expression of DR decreased more during the response of clinically isolated leukemic cells to retinyl palmitate. The increased expression of CD33 and CD34 was associated with the sensitivity of clinically isolated leukemia cells to retinyl palmitate and mevinolin. The results obtained indicate that the expression of CD22 was considered a positive surrogate marker for the increased sensitivity of clinically isolated leukemic cells to the plant-derived drugs tested, except for retinyl palmitate, salicin and cerulinin. In addition, CD4, CD14, CD33 and CD34 were shown to be candidate markers for good responses among the clinically isolated leukemic cells to plant-derived drugs. By contrast, CD22, MPO and DR were considered as resistance surrogate markers for clinically isolated leukemic cells in response to the tested plant-derived drugs (Fig. 3).

\section{Discussion}

Hematopoietic cancers constitute a diverse group of diseases including leukemias, lymphomas, plasma cell tumors, myelodysplastic syndromes, and mastocy tosis. They arise primarily from two categories of immunological cell types, myeloid and lymphoid cells (22). Malignancies of the lymphoid group are more widespread and the classification between lymphomas and leukemias has become controversial (22). It is well known that acute leukemia $(\mathrm{AL})$ is a group of heterogeneous 
diseases with varying clinical, morphologic, immunologic, and molecular characteristics. For example, ALL is highly heterogeneous with regards to chromosome translocations or molecular genetic abnormalities, which have distinct impacts on leukemogenesis and risk stratification processes (23-25). Therefore, the distinction between different subtypes of $\mathrm{AL}$ is of paramount importance, particularly to differentiate between lymphoid and myeloid leukemia. In this context, the WHO classification for AL has observed a paradigm shift to accommodate the complexity and heterogeneous nature of this ubiquitous group of malignancies (23). ALs exhibit the same pattern of antigen acquisition typically observed in normal hematopoietic differentiation, but invariably exhibit distinct aberrant immunophenotypic characteristics. Therefore, gaining a better understanding of these phenotypic patterns of differentiation, allowing for a more precise classification of leukemia than what morphology usually provides, is important. Molecular quantification of clonal rearrangements of IG/T-cell receptor genes or fusion genes by quantitative polymerase chain reaction $(26,27)$ and LAIPs by flow cytometry $(28,29)$ are the two most commonly used methods for classification.

The use of traditional medicine based on plants has received considerable interest (11,30-32). There are national and indigenous rights over plant-derived resources and human population genetics. Of note, basic scientific investigations on the clinical potential of medicinal plants and indigenous medical systems have been on the increase. A screening program was initiated over 30 years ago (33) identifying numerous antibacterial, antifungal, antiviral, antiparasitic, and other pharmacologically active substance activities in higher plants (34) using human cell lines from mainly northern European origins. Revisions of these, both for indigenous peoples and their plant therapeutics, are necessary. Eventually a mixture of natural products may serve as more efficient anticancer formulations. In this context, mixtures of plant-derived products are known as botanicals, which are defined by the US Food and Drug Administration as complete, labeled products that contain vegetable matter as ingredients, including plant materials, algae, macroscopic fungi, and combinations thereof (11). The majority of plant-derived treatments are based on synthetic, semisynthetic, or otherwise highly-purified or chemically-modified drugs. A recent survey of the pharmaceutical market revealed that the global plant-derived drug market was valued at US \$ 22.1 billion in 2012 and sales are projected to rise to US $\$ 26.6$ billion by 2017 at a compound annual growth rate of $3.8 \%$ (35). Of note, the botanical arsenal currently has only one approved drug, Veregen, with an expected revenue increase from US \$ 2.8 million in 2010 to 599 million in 2017 (35).

Due to the major health and economic impact of cancer and leukemia, considerable attention has been drawn to the identification of cytotoxic agents (1). The severe side effects of the majority of cytotoxic agents has led to scientific investigations in the direction of modifying treatment options or treatment modalities (36). The re-assessment of investigational drugs in the field of neoplasia is worthy of intensive investigation (37). In particular, natural compounds of mild to moderate adverse effects may be an essential field for investigational anticancer drug identification. In the present study, cerulenin and retinyl palmitate exhibited the most promising anti-leukemic effects in primary cell lines prepared from 15 indigenous Egyptian patients. The overexpression of the LAIPs, CD4, CD14, CD33 and CD34 were considered surrogate markers of 'good responses' for leukemic cells treated with compounds of natural origin (38-40). By contrast, the high expression of LAIPs including CD22, MPO and DR were regarded as resistance-associated surrogate markers with poor prognostic outcome to the treatment with natural products (37).

Pharmacogenomics is considered one of the most recent trends in drug identification, with particular significance in cancer therapeutics (41). Thus, 'tailor-made', as opposed to 'one size fits all' medicine based on the genetic background of the disease or the patient may provide a road map for better prognostic expectation, permitting oncologists to select the most effective therapy, depending on whether specific cancer gene mutations are found. In the present study, a diverse set of natural compound effects on clinically isolated leukemia cells was generated with careful consideration of immunophenotypic background of the disease. The genetic background of clinically isolated leukemic cells from the Egyptian population has not frequently been made available in the literature $(36,42)$. In the present study, preliminary evidence was provided of several LAIPs that serve as successful prognostic surrogate markers for treatment efficacy assessment in Egyptian leukemic patients. Findings of this study potentially formulate a solid springboard for future large-scale studies, including a library with a higher number of plant-derived drugs whose anti-leukemic potential remains to be investigated. A first step towards achieving this aim is to conduct surveys on the geographic distribution of hematopoietic cancers and particularly ALs in Egypt, such as the study reporting this approach in the Nile delta of Egypt (43). Elucidation of a more extended list of potential LAIP markers in different tribal and ethnic communities in Egypt and Arab countries is therefore required.

\section{Acknowledgements}

The study was funded by grants from the National CFIDS Foundation Inc., Needham, MA, USA.

\section{References}

1. Bennett JM, Catovsky D, Daniel MT, Flandrin G, Galton DA, Gralnick HR and Sultan C: Proposals for the classification of the acute leukaemias. French-American-British (FAB) co-operative group. Br J Haematol 33: 451-458, 1976.

2. Bain BJ: Acute leukemia cytology, cytochemistry and the FAB classification. In: Leukemia Diagnosis. Bain J (ed). Chapter 2, 2nd edition. Blackwell Science, Oxford, UK, pp1-52, 1999.

3. Bray F, Jemal A, Grey N, Ferlay J and Forman D: Global cancer transitions according to the Human Development Index (2008-2030): a population-based study. Lancet Oncol 13: 790-801, 2012.

4. American Cancer Society: Global Cancer Facts \& Figures. 3rd edition. American Cancer Society, Atlanta, GA, 2015.

5. American Cancer Society: Cancer Facts \& Figures 2014. American Cancer Society, Atlanta, GA, 2014.

6. Tadmouri GO, Nair P, Obeid T and Gallala S: Genetics Made Easy 2: Cancers. Center for Arab Genomic Studies. http://www. cags.org.ae/gme2cancersenleukemia.pdf. Accessed Feb 22, 2015.

7. El-Shemy HA, Aboul-Enein AM, Aboul-Enein MI, Issa SI and Fujita K: The effect of willow leaf extracts on human leukemic cells in vitro. J Biochem Mol Biol 36: 387-389, 2003. 
8. El-Shemy HA, Aboul-Enein AM, Aboul-Enein KM and Fujita K Willow leaves' extracts contain anti-tumor agents effective against three cell types. PLoS One 2: e178, 2007.

9. Elgendi HM, Mekawy MA, Abdel Wahab SE, Tawfik LM, Ismail EA and Adly AA: AC133 expression in egyptian children with acute leukemia: impact on treatment response and disease outcome. J Pediatr Hematol Oncol 32: 286-293, 2010.

10. No authors listed: All natural. Nat Chem Biol 3: 351, 2007.

11. Krause J and Tobin G: Discovery, Development, and Regulation of Natural Products. In: Using Old Solutions to New Problems - Natural Drug Discovery in the 21st Century. Marianna Kulka (ed). InTech, p424, Rijeka, Croatia, 2013.

12. Schwartsmann G: Marine organisms and other novel natural sources of new cancer drugs. Ann Oncol 11 (Suppl 3): 235-243, 2000.

13. McChesney JD, Venkataraman SK and Henri JT: Plant natural products: back to the future or into extinction? Phy tochemistry 68: 2015-2022, 2007.

14. Rout SP, Choudary KA, Kar DM, Das L and Jain A. Plants in traditional medicinal system - Future source of new drugs. Int J Pharm Pharm Sci 1: 1-23, 2009.

15. Beutler JA: Natural Products as a Foundation for Drug Discovery. Curr Protoc Pharmacol 46: 9.11.1-9.11.21, 2009

16. Cragg GM and Newman DJ: Plants as a source of anti-cancer agents. J Ethnopharmacol 100: 72-79, 2005.

17. Raskin I, Ribnicky DM, Komarnytsky S, Ilic N, Poulev A, Borisjuk N, Brinker A, Moreno DA, Ripoll C, Yakoby N, et al: Plants and human health in the twenty-first century. Trends Biotechnol 20: 522-531, 2002.

18. Kishimoto T, Kikutani H, Von dem Borne AEG, Jr Goyert SM, Mason DY, Miyasaka M, Moretta L, Okumura K, Shaw S, Springer TA, Sugamura K, Zola H (eds). Leukocyte Typing VI. White Cell Differentiation Antigens. Garland Publishing, Inc. New York, NY, 1997.

19. Harris NL,Jaffe ES, Diebold J,Flandrin G, Muller-Hermelink HK Vardiman J, Lister TA and Bloomfield CD: World Health Organization classification of neoplastic diseases of the hematopoietic and lymphoid tissues: Report of the Clinical Advisory Committee meeting-Airlie House, Virginia, November 1997 J Clin Oncol 17: 3835-3849, 1999.

20. Borowitz MJ and Chan JK: Precursor lymphoid neoplasms In: WHO classification of tumours of haematopoietic and lymphoid tissues. Swerdlow SH, Campo E, Harris NL, et al (eds). 4th edition. International Agency for Research on Cancer, Lyon, pp167-178, 2008

21. Xu F, Yin CX, Wang CL, et al: Immunophenotypes and Immune Markers Associated with Acute Promyelocytic Leukemia Prognosis. Dis Markers 2014: 421906, 2014.

22. Robbins SL, Kumar V and Cotran RS: Robbins and Cotran Pathologic Basis of Disease. Elsevier, Philadelphia, PA, 2010.

23. Fielding AK: Current treatment of Philadelphia chromosome-positive acute lymphoblastic leukemia. Hematology (Am Soc Hematol Educ Program) 2011: 231-237, 2011.

24. Chen B, Wang YY, Shen Y, Zhang WN, He HY, Zhu YM, Chen HM, Gu CH, Fan X, Chen JM, et al: Newly diagnosed acute lymphoblastic leukemia in China (I): abnormal genetic patterns in 1346 childhood and adult cases and their comparison with the reports from Western countries. Leukemia 26: 1608-1616, 2012.

25. Mi JQ, Wang X, Yao Y, Lu HJ, Jiang XX, Zhou JF, Wang JH, Jiao B, Shen SH, Tang JY, et al: Newly diagnosed acute lymphoblastic leukemia in China (II): prognosis related to genetic abnormalities in a series of 1091 cases. Leukemia 26: 1507-1516, 2012.

26. Brüggemann M, Droese J, Bolz I, Lüth P, Pott C, von Neuhoff N Scheuering $U$ and Kneba M: Improved assessment of minimal residual disease in $\mathrm{B}$ cell malignancies using fluorogenic consensus probes for real-time quantitative PCR. Leukemia 14 $1419-1425,2000$
27. Kerst G, Kreyenberg H, Roth C, Well C, Dietz K, Coustan-Smith E, Campana D, Koscielniak E, Niemeyer C, Schlegel PG, et al: Concurrent detection of minimal residual disease (MRD) in childhood acute lymphoblastic leukaemia by flow cytometry and real-time PCR. Br J Haematol 128: 774-782, 2005.

28. Salem DA and Abd El-Aziz SM: Flowcytometric immunophenotypic profile of acute leukemia: mansoura experience. Indian J Hematol Blood Transfus 28: 89-96, 2012.

29. Denys B, van der Sluijs-Gelling AJ, Homburg C, van der Schoot CE, de Haas V, Philippé J, Pieters R, van Dongen JJ and van der Velden VH: Improved flow cytometric detection of minimal residual disease in childhood acute lymphoblastic leukemia. Leukemia 27: 635-641, 2013.

30. El-Shemy HA, Aboul-Soud MA, Nassr-Allah AA, Aboul-Enein KM, Kabash A and Yagi A: Antitumor properties and modulation of antioxidant enzymes' activity by Aloe vera leaf active principles isolated via supercritical carbon dioxide extraction. Curr Med Chem 17: 129-138, 2010.

31. Han SS, Keum YS, Seo HJ and Surh YJ: Curcumin suppresses activation of NF-kappaB and AP-1 induced by phorbol ester in cultured human promyelocytic leukemia cells. J Biochem Mol Biol 35: 337-342, 2002.

32. Shanab SM, Shalaby EA, Lightfoot DA and El-Shemy HA: Allelopathic effects of water hyacinth (Eichhornia crassipes). PLoS One 5: e13200, 2010.

33. Ieven M, Vanden Berghe DA, Mertens F, Vlietinck A and Lammens E: Screening of higher plants for biological activities. I. Antimicrobial activity. Planta Med 36: 311-321, 1979.

34. Jang M, Cai L, Udeani GO, Slowing KV, Thomas CF, Beecher CW, Fong HH, Farnsworth NR, Kinghorn AD, Mehta RG, et al: Cancer chemopreventive activity of resveratrol, a natural product derived from grapes. Science 275: 218-220, 1997.

35. Lawson K: Botanical and Plant-derived Drugs: Global Markets. BCC Research, 2013.

36. Shaked Y, Emmenegger U, Francia G, Chen L, Lee CR, Man S, Paraghamian A, Ben-David Y and Kerbel RS: Low-dose metronomic combined with intermittent bolus-dose cyclophosphamide is an effective long-term chemotherapy treatment strategy. Cancer Res 65: 7045-7051, 2005.

37. Onodera T, Poe JC, Tedder TF and Tsubata T: CD22 regulates time course of both $\mathrm{B}$ cell division and antibody response. J Immunol 180: 907-913, 2008.

38. Forsyth RG, De Boeck G, Baelde JJ, Taminiau AH, Uyttendaele D, Roels H, Praet MM and Hogendoorn PC: CD33+ CD14- phenotype is characteristic of multinuclear osteoclast-like cells in giant cell tumor of bone. J Bone Miner Res 24: 70-77, 2009.

39. Gorin NC, Labopin M, Reiffers J, Milpied N, Blaise D, Witz F, de Witte T, Meloni G, Attal M, Bernal T, et al; Acute Leukemia Working Party, European Cooperative Group for Blood and Marrow Transplantation: Higher incidence of relapse in patients with acute myelocytic leukemia infused with higher doses of CD34+ cells from leukapheresis products autografted during the first remission. Blood 116: 3157-3162, 2010.

40. Kamel AM, Assem MM, Jaffe ES, Magrath I, Aboul Enein MI and Hindawy DS: Immunological phenotypic pattern of acute lymphoblastic leukaemia in Egypt. Leuk Res 13: 519-525, 1989.

41. McDermott U and Settleman J: Personalized cancer therapy with selective kinase inhibitors: an emerging paradigm in medical oncology. J Clin Oncol 27: 5650-5659, 2009.

42. Tantawy AA, El-Bostany EA, Adly AA, Abou El Asrar M, El-Ghouroury EA and Abdulghaffar EE: Methylene tetrahydrofolate reductase gene polymorphism in Egyptian children with acute lymphoblastic leukemia. Blood Coagul Fibrinolysis 21: 28-34, 2010.

43. Herzog CM, Dey S, Hablas A, et al: Geographic distribution of hematopoietic cancers in the Nile delta of Egypt. Ann Oncol 23: 2748-2755, 2012. 